\title{
Synthesis of Well-Defined Allyl End-Functionalized Polystyrene by Atom Transfer Radical Polymerization with an Allyl Halide Initiator
}

\author{
Yoshiki Nakagawa and Krzysztof Matyjaszewski ${ }^{\dagger}$ \\ Department of Chemistry, Carnegie Mellon University, \\ 4400 Fifth Ave., Pittsburgh, PA 15213, U.S.A.
}

(Received August 15, 1997)

\begin{abstract}
The allyl chloride and allyl bromide initiated atom transfer radical polymerization, ATRP, of styrene was conducted to afford $\alpha$-allyl- $\omega$-halopolystyrene with molecular weights predetermined by $\Delta[\mathrm{M}] /[\mathrm{I}]_{0}$ and with low polydispersities, $M_{w} / M_{n} \approx 1.2$ for allyl bromide and $M_{w} / M_{n} \approx 1.3$ for allyl chloride. The structure of the $\alpha$-allyl- $\omega$-halopolystyrene was confirmed by ${ }^{1} \mathrm{H}$ NMR spectra. The halogen end-groups were transformed to azido group quantitatively with trimethylsilyl azide in the presence of tetrabutylammonium fluoride.

KEY WORDS Allyl/Atom Transfer Radical Polymerization / Azide / End Functional Polymers / Living Radical Polymerization / Polystyrene /
\end{abstract}

Recently, the study of "living"/controlled free radical polymerization has flourished with the development of several methods. ${ }^{1-14}$ Among them, we have developed atom transfer radical polymerization (ATPR), which is catalyzed by metal halides complexed with 2,2'-bipyridine (bipy) derivatives. ${ }^{6-12,15}$ This polymerization system has provided well-defined polymers with low polydispersities $\left(1.05<M_{w} / M_{n}<1.5\right)$, and degrees of polymerization predetermined by the ratio of concentrations of reacted monomer and introduced initiator $\left(D P_{n}=\right.$ $\left.\Delta[\mathrm{M}] /[\mathrm{I}]_{0}\right)$.

ATRP can be initiated by several halide containing initiators such as benzyl halide, methyl 2-halopropionate, 2-bromopropionitrile, $p$-tosyl chloride, etc. ${ }^{10,12}$ If an initiator containing a functional group is used for ATRP, end-functionalized polymers can be readily prepared. ${ }^{16}$ End-functionalized polymers are very important not only in academia but also in industry.

The allyl group is a versatile one which can be transformed to many kinds of other functional groups such as epoxy, hydroxy, etc. Also, allyl end-functionalized polymer can be used for the synthesis of block and graft copolymers via hydrosilylation. ${ }^{17}$

In ATRP, the allyl halides are considered to produce radicals by homolytic cleavage of the $\mathrm{C}-\mathrm{X}$ bond upon reaction with $\mathrm{Cu}(\mathrm{I})$. If allyl halides are efficient initiators of ATRP, they would provide a simple method to produce well-defined allyl end-functionalized polymers. In this paper we report the simple and effective synthesis of well-defined $\alpha$-allyl- $\omega$-halopolystyrenes prepared by ATRP with allyl bromide and chloride initiators. The transformation of the halogen end-group to an azide is also discussed.

\section{RESULTS AND DISCUSSION}

ATRP of styrene with allyl halide initiators was carried out under reaction conditions similar to those for other initiators such as 1-phenylethyl bromide (Scheme 1). ${ }^{9,11-13,15}$ The polymerization of styrene with allyl bromide, or chloride, was conducted using the $\mathrm{Cu}(\mathrm{I}) \mathrm{Br}$ (or $\mathrm{Cu}(\mathrm{I}) \mathrm{Cl}$ )/bipy catalyst in phenyl ether under argon. The polymerization using chloride was carried out at $130^{\circ} \mathrm{C}$; using bromide at $100^{\circ} \mathrm{C}$. The first-order kinetic plots for the polymerizations are shown in Figure 1. The plots were linear to over $85 \%$ conversion, indicating that there was no significant termination reactions during the polymerization. The polymerization initiated by allyl iodide with a $\mathrm{Cu}(\mathrm{I}) \mathrm{I} /$ bipy catalyst was attempted under similar conditions but no polymerization was observed, presumably due to the decomposition of iodo-terminated polystyrene chains by elimination of $\mathrm{HI}$.

The dependence of molecular weight and polydispersity with conversion for the polymerizations initiated by allyl bromide and allyl chloride is shown in Figure 2. A linear increase in number average molecular weight, $M_{n}$, versus monomer conversion was observed. The observed $M_{n}$ was close to the theoretical values in the both cases, although initially the molecular weights were slightly higher than expected, especially for allyl chloride, which may be a less efficient initiator. These results indicated that no significant transfer reactions occurred during the polymerization. The molecular weight distributions were relatively narrow, $M_{w} / M_{n} \approx 1.2$ for allyl bromide and $M_{w} / M_{n} \approx 1.3$ for allyl chloride. The catalyst system, when using $\mathrm{Cu}(\mathrm{I}) \mathrm{X} /$ bipy complexes, was heterogeneous. The polydispersity may be potentially reduced with homogeneous catalysts such as $\mathrm{CuX} / 4,4^{\prime}$ $\operatorname{di}\left(5\right.$-nonyl)-2,2'-bipyridine. ${ }^{15}$

The structure of the $\alpha$-allyl- $\omega$-halopolystyrene was confirmed by ${ }^{1} \mathrm{H}$ NMR spectroscopy. Figure 3 shows the ${ }^{1} \mathrm{H}$ NMR spectrum of $\alpha$-allyl- $\omega$-chloropolystyrene. The peaks at $4.7-4.9 \mathrm{ppm}$ were assigned to the two terminal protons on the double bond; the internal proton at $5.5-5.7 \mathrm{ppm}$; and the proton geminal to chloride group at $4.2-4.5 \mathrm{ppm}$. The ratio of the integration of the three peaks was $1: 2: 1$, which was in agreement with

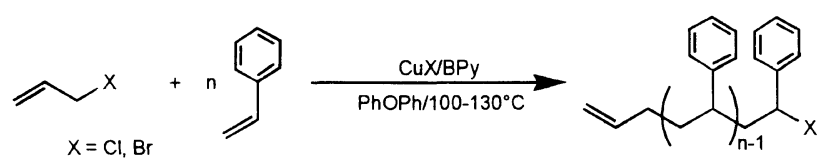

\footnotetext{
† To whom correspondence should be addressed.
} 


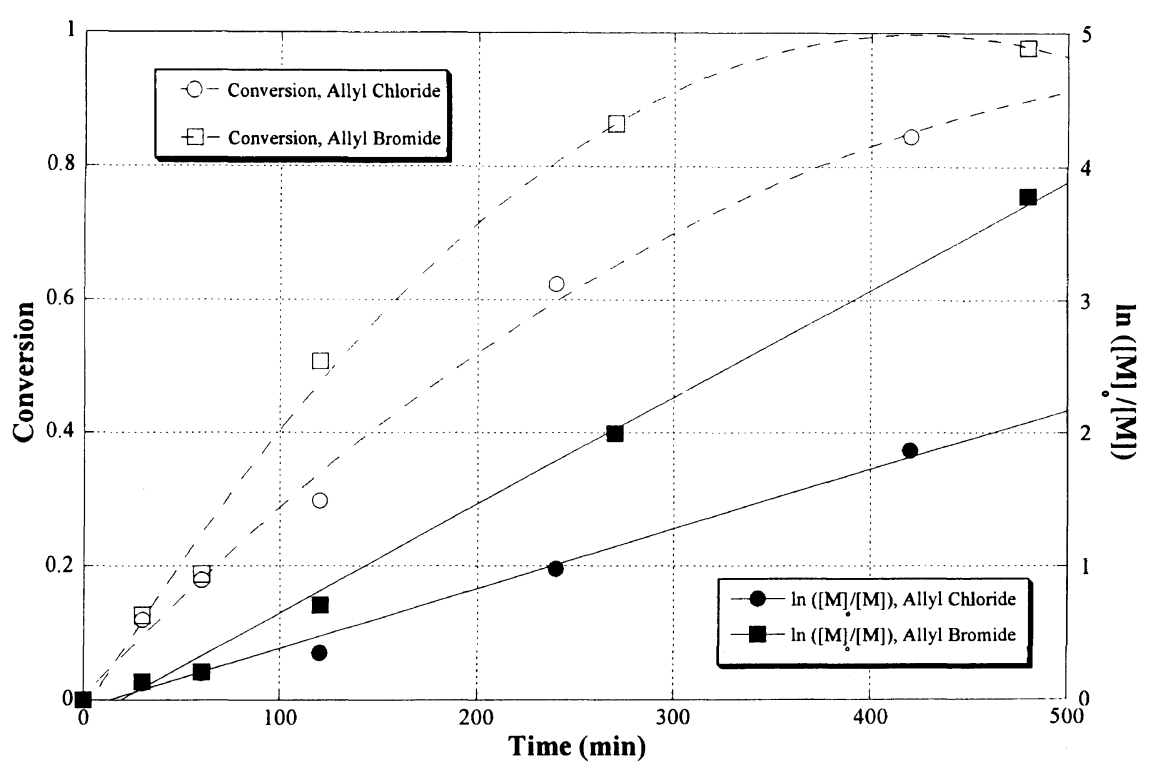

Figure 1. First order kinetic plots for the ATRP of styrene in phenyl ether initiated by allyl bromide at $100^{\circ} \mathrm{C}$ and allyl chloride at $130^{\circ} \mathrm{C}$.

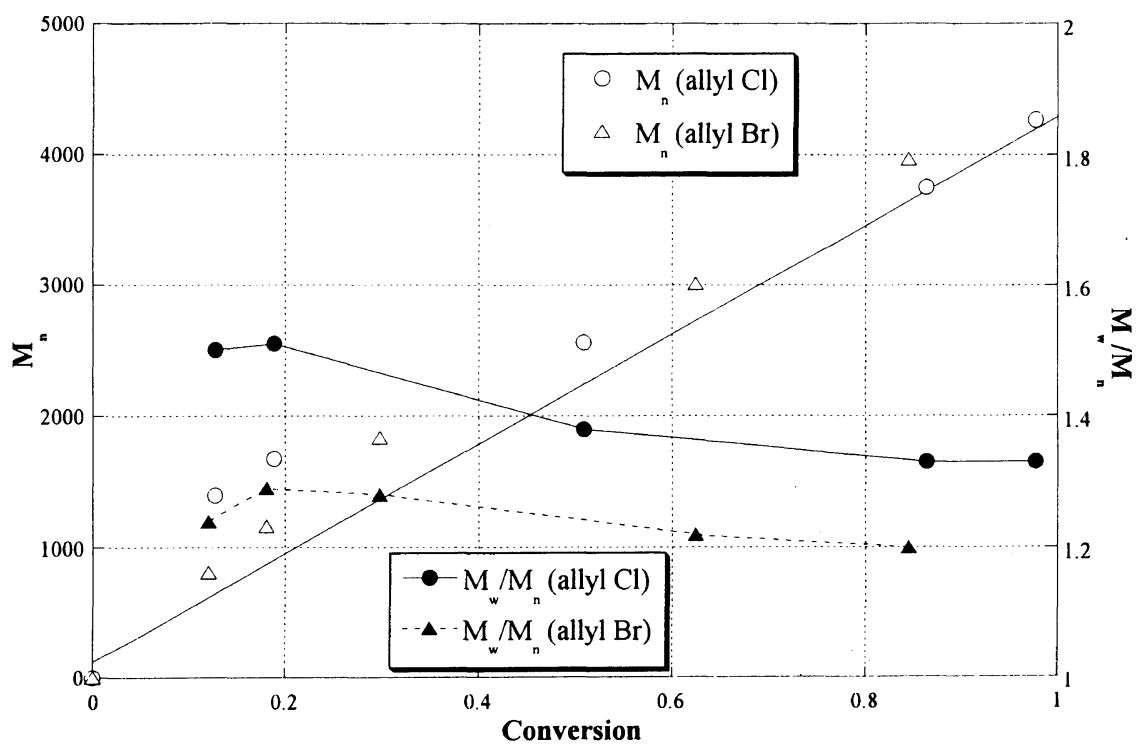

Figure 2. $M_{n}$ and polydispersity versus conversion for the ATRP of styrene in phenyl ether with allyl bromide at $100^{\circ} \mathrm{C}$ and allyl chloride at $130^{\circ} \mathrm{C}$. (Solid line indicates theoretical $M_{n}$.)

the structure of the polymer. Neither peaks assignable to elimination products $(\approx 6.3 \mathrm{ppm})$, nor peaks assignable to hydrogen transfer $(\approx 1.2 \mathrm{ppm})$ were observed. The results indicated that allyl chloride initiated the atom transfer radical polymerization of styrene quantitatively, and no detectable side reactions occurred during the polymerization.

The halogen end-groups of $\alpha$-allyl- $\omega$-halopolystyrene were transformed to azide groups with trimethylsilyl azide in the presence of tetrabutylammonium fluoride (Scheme 2). The transformation was carried out for the bromo-terminated polymer at room temperature and for the chloro-terminated polymer at $40^{\circ} \mathrm{C}$.

Figure 4 shows the ${ }^{1} \mathrm{H}$ NMR spectrum of $\alpha$-allyl- $\omega$ azidopolystyrene which was prepared from $\alpha$-allyl- $\omega$ bromopolystyrene. The ratio of peaks of the olefinic protons on the allyl group and the proton geminal to the azido group was maintained at the same $1: 2: 1$ ratio, indicating that the transformation from halogen to azide

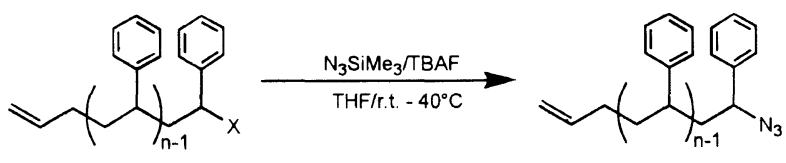

Scheme 2.

was quantitative.

\section{CONCLUSION}

Allyl chloride and allyl bromide initiated atom transfer radical polymerization of styrene afforded $\alpha$-allyl- $\omega$ halopolystyrenes with molecular weights predetermined by $\Delta[\mathrm{M}] /[\mathrm{I}]_{0}$ and with low polydispersities. The halogen end-groups were transformed to azido groups quantitatively with trimethylsilyl azide in the presence of tetrabutylammonium fluoride. 


\section{EXPERIMENTAL}

\section{Materials}

Styrene (from Acros) was passed through a column of alumina then bubbled with argon. $\mathrm{Cu}(\mathrm{I}) \mathrm{Br}$ and $\mathrm{Cu}(\mathrm{I}) \mathrm{Cl}$ were purified by stirring in acetic acid, washing with methanol then drying. Tetrahydrofuran (THF) was distilled from sodium. Phenyl ether (from Acros) was dried over molecular sieves. 2,2'-Bipyridine (bipy) (from Acros) was recrystallized from $n$-hexane. All other reagents were used as received.

\section{Analysis}

GPC measurements were carried out by using a Waters 510 liquid chromatography equipped with four Phenogel



columns (100 $\AA, 1000 \AA$, linear and guard) in series with a 410 differential refractometer and a Waters $991 \mathrm{UV}$ detector. Calibration was based on narrow molecular weight polystyrene standards using Polymer Standards Service's software. A $300 \mathrm{MHz}$ Brüker spectrometer was used for ${ }^{1} \mathrm{H}$ NMR analysis.

\section{Polymerization of Styrene with Allyl Bromide}

The polymerization was carried out in a previously dried flask equipped with a magnetic stirring bar under argon. The flask was charged with phenyl ether $(10.0 \mathrm{~g})$, $\mathrm{CuBr}\left(0.313 \mathrm{~g} ; 2.18 \times 10^{-3} \mathrm{~mol}\right)$ and $2,2^{\prime}$-bipyridine $\left(1.021 \mathrm{~g} ; 6.54 \times 10^{-3} \mathrm{~mol}\right)$. The flask was sealed with a rubber septum, and then cycled between vacuum and argon three times to remove oxygen. Degassed styrene $\left(10.0 \mathrm{ml} ; 8.73 \times 10^{-2} \mathrm{~mol}\right)$ was added via syringe. Allyl bromide $\left(0.189 \mathrm{ml} ; 2.18 \times 10^{-3} \mathrm{~mol}\right)$ was added and the flask was immersed in an oil bath held by a thermostat at $100^{\circ} \mathrm{C}$. The conversion of the polymerization was determined by GLC measurement of sampled reaction mixture. After $420 \mathrm{~min}$ the heating was stopped, and the conversion was $85 \%$. The reaction mixture was poured into methanol. The precipitated polymer was purified by means of a short alumina column, followed by reprecipitation into methanol from THF.

\section{Polymerization of Styrene with Allyl Chloride}

In a similar manner to allyl bromide, polymerization of styrene initiated by allyl chloride was performed with phenyl ether $(10.0 \mathrm{~g}), \mathrm{CuBr}\left(0.216 \mathrm{~g} ; 2.18 \times 10^{-3} \mathrm{~mol}\right)$, $2,2^{\prime}$-bipyridine $\left(1.021 \mathrm{~g} ; 6.54 \times 10^{-3} \mathrm{~mol}\right)$, styrene $(10.0$ $\left.\mathrm{ml} ; 8.73 \times 10^{-2} \mathrm{~mol}\right)$, and allyl chloride $(0.178 \mathrm{ml}$; $\left.2.18 \times 10^{-3} \mathrm{~mol}\right)$ at $130^{\circ} \mathrm{C}$. After $480 \mathrm{~min}$ the heating was stopped, the conversion was $98 \%$. The reaction mixture was worked up in a similar manner as described above.

Figure 3. ${ }^{1} \mathrm{H}$ NMR spectrum $\alpha$-allyl- $\omega$-chloropolystyrene $\left(M_{n}=\right.$ 4100).

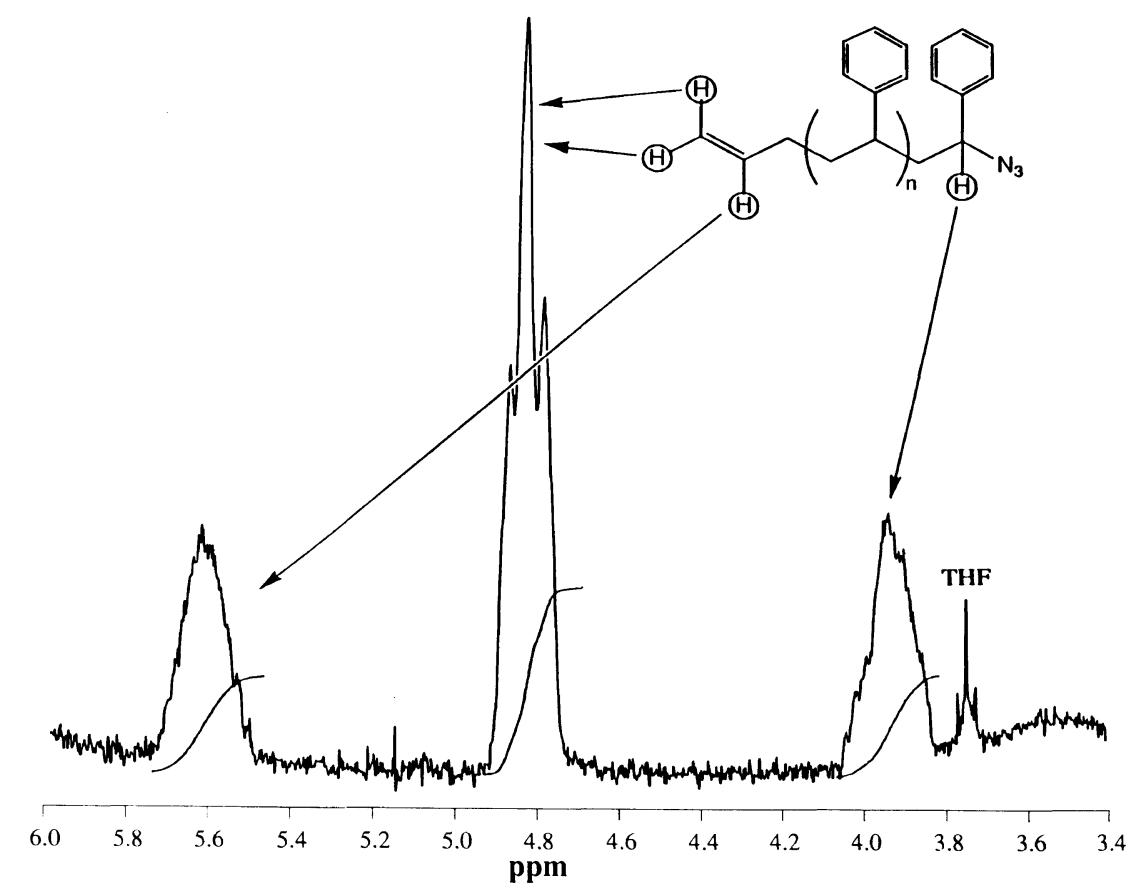

Figure 4. ${ }^{1} \mathrm{H}$ NMR spectrum of the region specific for end groups in $\alpha$-allyl- $\omega$-azidopolystyrene $\left(M_{n}=4100\right)$. 
Transformation of Bromo End-Group to Azido Group

Under dry conditions, a dry round-bottom flask was charged with $\alpha$-allyl- $\omega$-bromopolystyrene $(1.0 \mathrm{~g})$, trimethylsilyl azide $\left(0.083 \mathrm{ml} ; 6.28 \times 10^{-4} \mathrm{~mol}\right)$, tetra $(n-$ butyl) ammonium fluoride (TBAF) solution (1.0 M THF solution; $\left.0.628 \mathrm{ml} ; 6.28 \times 10^{-4} \mathrm{~mol}\right)$ and THF $(4.0 \mathrm{ml})$. The mixture was stirred at room temperature under argon for 1 day. Disappearance of the bromo end-group was confirmed by ${ }^{1} \mathrm{H}$ NMR. The reaction mixture was poured into methanol, and the precipitated polymer was dried.

\section{Transformation of Chloro End-Group to Azido Group}

In a similar manner to $\alpha$-alloyl- $\omega$-bromopolystyrene, azidation of $\alpha$-allyl- $\omega$-chloropolystyrene was performed at $40^{\circ} \mathrm{C}$ in 1 day.

Acknowledgments. The authors wish to acknowledge the Industrial Members of the ATRP Consortium at Carnegie Mellon University and the National Science Foundation for partial support of this research. Y.N. acknowledges support from Kaneka Corp.

\section{REFERENCES}

1. D. H. Solomon, E. Rizzardo, and P. Cacioli, US Patent, 4,581,429 (1985)
2. M. K. Georges, R. P. N. Veregin, P. M. Kazmaier, and G. K. Hamer, Macromolecules, 26, 2987 (1993).

3. B. B. Wayland, G. Pszmik, S. L. Mukerjee, and M. Fryd, J. Am. Chem. Soc., 116, 7943 (1994)

4. S. G. Gaynor, J. S. Wang, and K. Matyjaszewski, Macromolecules, 28, 8051 (1995).

5. J. Krstina, G. Moad, E. Rizzardo, C. L. Winzor, C. T. Berge, and M. Fryd, Macromolecules, 28, 5381 (1995).

6. M. Kato, M. Kamigaito, M. Sawamoto, and T. Higashimura, Macromolecules, 28, 1721 (1995).

7. C. Granel, P. Dubois, R. Jerome, and P. Teyssie, Macromolecules, 29, 8576 (1996).

8. H. Uegaki, Y. Kotani, M. Kamigaito, and M. Sawamoto, Macromolecules, 30, 2249 (1997).

9. J. S. Wang and K. Matyjaszewski, Macromolecules, 28, 7572 (1995).

10. K. Matyjaszewski and J.-S. Wang, Macromolecules, 28, 7901 (1995).

11. K. Matyjaszewski, T. Patten, J. Xia, and T. Abernathy, Science, 272, 866 (1996).

12. V. Percec, B. Barboiu, A. Newmann, J. C. Ronda, and H. Zhao, Macromolecules, 29, 3665 (1996).

13. K. Matyjaszewski and J. Qiu, Macromolecules 30, 5643 (1977).

14. D. M. Haddleton, M. C. Crossman, K. H. Hunt, C. Topping, C. Waterson, and K. G. Suddaby, Macromolecules, 30, 3992 (1997).

15. K. Matyjaszewski, T. E. Patten, and J. Xia, J. Am. Chem. Soc., 119, 674 (1997).

16. K. Matyjaszewski, S. Coca, Y. Nakagawa, and J. H. Xia, Polym. Mater. Sci. Eng., 76, 147 (1997).

17. V. Compan, M. A. Villar, E. Valles, and E. Riande, Polymer, 37, 101 (1996). 